234 A PERINATAL RESEARCH DATABASE. Richard W. Krouskop, 534 (spon, by Edwin G. Brown), Division of Neonatold Pediatrics, New York, New York.

A computerized perinatal database has been developed at Mount Sinai Hospital to manage information generated by 7000 admissions per year $(3500$ to the Newborn Special Care Unit. The unique database system occur in 3 areas.

1. It was designed from inception as a comprehensive, integrated maternal-infant database. There are currently 534 maternal and 646 infant variables. The database is designed to prospectively collect data of general utility to any perinatal research study enabling integration of that data with the specialized data collected by specific research.

collected by specific research.
2 . The database is distributed over two separate computer systems to be cost-effective, yet allow complex use of the data. Data are entered on a 16-bit multi-user micro-computer where admission notes, discharge summaries, and sumnary reports on $<1$ year's data are generated. Data are regularly transmitted from the local computer to our University Computing Center where complex statistical analysis, long-term analysis, and archival storage are avallable.

3. Data collection has been integrated into routine medical care, utilizing problem oriented records to allow prospective data collection rather than retrospective chart abstraction.

\section{$\dagger 537$}

IMMUNITY OF YOUNG ADULTS TO CHILOHOOD DISEASES. Alan

Science Center, San Antonio, Texas. Epidemics of measles and rubella on college campuses
stimulated us to study the immune status of similar age stimulated us to study the immune status of similar age
individuals. Plasma collected for routine laboratory studies at entrance to nursing or dental school were tested by Enzyme Linked Immunosorbent Assay (ELISA) for varicella (V), measles and mumps (MM) antibody. To define the seronegative range, tests were standardized for M\&M by testing 45 sera obtained from children prior to immunization and for $V$ by testing 24 sera obtained prior to infection. The number of sera falling within 3 SD of the mean of seronegatives in relation to the total number of sera tested were: Mumps $11 / 235$ (4.7\%); Measles $3 / 235$ (1.3\%); and Varicella $6 / 235$ (2.5\%). On the day sera were obtained, 99 students were given MMR on the basis of historical data. Five seronegative for mumps and 2 for measles were not immunized; the latter had "physician documented measles." Thus, half the students needing protection against MMR were not imunized, while many others not requiring vaccine received

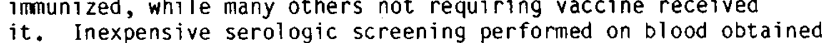
it. Inexpensive serologic screening performed on blood obtained
for other routine laboratory tests can identify the few students requiring vaccine including those who, on the basis of current historical criteria, would not have been immunized.

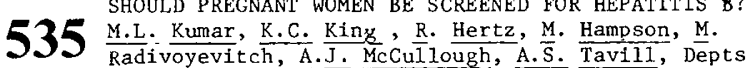
of Ped., Ob-Gyn., Path., and Medicine, Cleveland Metro. Gen. Hospital, Cleveland, Ohio.

Infants of $\mathrm{HB} \mathrm{Ag}(+)$ mothers are at risk for acquisition of hepatitis B virus (HBV) infection. In January 1983 we initiated an intrapartum screening program for $\mathrm{HB}$ Ag. In 11 months 3050 women have been tested with 19 positive subjects $(0.6 \%)$. Eighteen were asymptomat1c and one had acute HBV infection. 13 women were black (11 Americans, 2 Africans), 3 white, 2 Hispanic, and 1 Asian. Thirteen women received prenatal care in the clinic, 4( 2 blacks and 2 Hispanics) were cared for by private physicians, and 2 received no prenatal care. Routine prenatal care cians, and 2 received no prenatal care. Routine prenatal care Reassessment following delivery revealed defined HBV risk facReassessment following delivery revealed defined $\mathrm{HBV}$ risk fac-
tors in 6 subjects, including ethnic risk (2 Africans, 2 Hispanics, and 1 Southeast Asian) and IV drug abuse ( 1 subject). Five additional subjects had a history of prior hepatitis in a family member. One asymptomatic carrier was $\mathrm{HB} A \mathrm{Ag}(+)$. Two mothers delivered preterm infants including the mother with acute $\mathrm{HBV}$ and the asymptomatic $\mathrm{HB} \mathrm{Ag}(+)$ carrier. Mean birth weight for the 17 term infants was $2977 \mathrm{gms}$. Al1 infants were $\mathrm{HB}$ Ag $(-)$, and received hepatitis B immunoglobulin. Follow-up $\mathrm{HB} \mathrm{Ag}(-)$, and received hepatitis $\mathrm{B}$ immunoglobulin. Follow-up
studies on the infants are in progress. To date, all infants studies on the infants are in progress. To date, all infants
remain $\mathrm{HB} \mathrm{Ag} \mathrm{(-).} \mathrm{In} \mathrm{view} \mathrm{of} \mathrm{previously} \mathrm{published} \mathrm{estimates} \mathrm{of}$ remain $\mathrm{HB} \mathrm{Ag}(-)$. In view of previously published estimates of
the risk for development of $\mathrm{HBV}$ infection in neonates of $\mathrm{HB} \mathrm{Ag}$ $(+)$ mothers, the current program suggests that prenatal screening and appropriate immunoprophylaxis can reduce that risk.

536

EFFECT OF SUSCEPTIBILITY TESTING ON THE IMPACT OF NOSOCOMIAL VARICELLLA EXPOSURE. Philip and Robert Holzman. New York University School of Medicine, Depts. Pediatrics and Medicine, New York, N.Y.

A pregnant woman with a rash initially diagnosed as scabies delivered a healthy infant in the hospital. When varicella (V) was diagnosed, she was isolated, but she had already esposed 55 patients ( 35 women, 20 newborns) and 118 hospital staff. Forty-three/153 (28\%) of adults, including the mothers of six exposed newborns had no history of $\mathrm{V}$. These 43 adults were mothers of six exposed newborns had no history of (fluorescent antibody to tested for susceptibility to V by ELISA, PAMA (fluorescent antibody to
membrane antigen), and an intradermal V skin test (ST). The number of membrane antigen), and an intradermal $V$ skin test (ST). The number of
susceptibles was $7 / 43$ by ELISA; with 5 additional subjects having susceptibles was $7 / 43$ by ELISA; with 5 additional subjects having
equivocal ELISA results, $7 / 43$ by FAMA, and $2 / 25$ by ST (both FAMA susceptible). Susceptible staff were furloughed when potentially communicable. High risk susceptible patients were given VZIG. No secondary cases of $\mathrm{V}$ were identified. Institution of control measures consumed 154 hours of staff time. The cost of staff furlough $(\$ 12,000)$, VZIG $(\$ 675)$, and serologic testing $(\$ 1,200)$ was lower than it would have been if staff were furloughed based only on history $(\$ 80,000)$ or if based been if staff were furloughed based only on history $(\$ 80,000)$ or if based
on the cost of closing the obstetric and newborn services for the period of on the cost of closing the obstetric and newborn services for the period of
risk $(\$ 303,000)$. The ability to establish immune status dramatically reduced the financial impact of this occurrence and enabled us to continue the delivery of health care. Experience in 82 adults has shown agreement between ST and FAMA in all but $3(r=0.90)$. ST is easy and potentially widely available. ST's value as a predictor of immunity deserves fur ther study.

\begin{abstract}
$+\quad$ GROWTH DEFICIENCIES IN MEXICAN-AMERICAN CHILDREN IN † 538 THE UNITED STATES. Fernando S. Mendoza and Ricaxdo and University of California, San Francisco, Dept. of Peds. Sponsored by Ruth T. Gross.

The nutritional status of Mexican-American (M-A) children was evaluated by analyzing data from the National Health and Nutrition Examination Survey I (1971-1974), a probability survey of the nutritional and health status of the United States population. A subsample comprised of $M-A$ children $(\mathrm{N}=335)$, ages $1-19$ years was compared with non-Hispanic $(\mathrm{N}-\mathrm{H})$ children of the same age $(\mathrm{N}=6728)$. The groups' mean height, weight, and caloric intake were compared, controlled for socioeconomic status (SES). The $M-A$ childrens' height and weight percentiles wexe also examined the M-A sample was significantly smaller in both height and the $\mathrm{M}-\mathrm{A}$ sample was significantly smaller in both height and
weight than the $\mathrm{N}-\mathrm{H}$ group (H: $\mathrm{p}<.001, \mathrm{~W}: \mathrm{p}<05$ ). The lowest SES $M-A$ group was significantly smaller than the comparable $\mathrm{N}-\mathrm{H}$ group (H: $\mathrm{P}<.01, \mathrm{~W}: \mathrm{p}<.02$ ). These differences were not present among higher SES groups. Within the M-A sample, the mean height and weight was significantly smallex for the low SES group ( $<<05$ ). The examination of the growth percentiles revealed that $10 \%$ of $\mathrm{M}-\mathrm{A}$ children were below the 5 th percentile in height. A similar comparison of weight pexcentiles did not demonstrate a difference. $M-A$ children in the lowest SES group had caloric intakes significantly lower than comparable $\mathrm{N}-\mathrm{H}$ groups or higher SES groups among $M-A$. Conclusion: There are significant growth differences between $M-A$ and $N-H$ children which are affected by SES. This suggests that malnutrition may be a concern among $M-A$ children.
\end{abstract}

HAS CARCINOGENESIS OCCURRED AFTER CHILDHOOD EXPOSURE

539 TO ASBESTOS-SPRAYED SCHOOLROOM CEILINGS? Robert W. Institute, Clinical Epidemiology and Biometry Branches, Bethesda.

Does deterioration of asbestos sprayed on the ceilings of about $10 \%$ of U.S. schools cause mesothelioma or, in conjunction with cigarette-smoking, bronchogenic carcinoma after this childhood exposure? The spraying of ceilings began in the late 1940s (Spooner, CM: New Eng. J. Med. 301:782, 1979) and because of the time it takes for the fraying to occur and the latent period (at least 20 years) for the neoplasia, one would expect insufficient time to have passed to detect a carcinogenic effect. Several school maintenance men have developed mesothelioma, however, and therefore a simple check of U.S. cancer statistics for young adults was made to see if an upturn has occurred in the frequency of either of these two cancers. Neither death-certificate data for the U.S., 1950-1980, nor incidence data, 1973-1980, from the Surveiliance, Epidemiology and End-Results Program of the NCI showed an increase in agespecific trends among young adults in recent years for either neoplasm. The negative results to date may be due to exposures that were too low, or latent periods that are too long for the interval that $c$ an be studied at present. Persons so exposed as children should be urged not to smoke. 